\title{
Comparative Study Between High Resolution Ultrasound with Histopathological Examination in the Diagnosis of Lesions of The Thyroid Gland
}

\author{
Dr. Yogeesha B.S ${ }^{1}$ Dr. Venkatesha B.K. ${ }^{2}$ Dr. Asha M. $^{3}$ \\ ${ }^{1}$ associate Professor, Department Of Otorhinolaryngology S.S. Institute Of Medical Sciences \& Research \\ Centre. Davangere -577005, Karnataka, India \\ ${ }^{2}$ associate Professor, Department Of Otorhinolaryngology,S. S. Institute Of Medical Sciences \& Research \\ Centre. Davnagere-577005, Karnataka, India \\ ${ }^{3}$ resident, Department Of Otorhinolaryngology, S. S. Institute Of Medical Sciences \& Research Centre.
} Davnagere-577005, Karnataka, India

\begin{abstract}
The diseases of thyroid form a major share of head and neck surgery. Clinical examination although very accurate in most cases, is inadequate in most areas especially in staging of thyroid malignancies and in detecting the multinodularity of the gland. The present study was undertaken to compare the efficacy of high resolution USG with final HPE diagnosis.

The present study is a prospective study of patients presenting with clinical suspicion of thyroid diseases referred to the department of Otorhinolaryngology, SSIMS\&RC, Davangere from January 2015 to December 2015. Sensitivity, specificity, positive predictive value and negative predictive value of USG in comparison to HPE for benign lesions were 100\%, 25\%, 89.66\% and 100\% and for malignant lesions were $25 \%, 100 \%, 100 \%$ and $89.66 \%$ respectively. High resolution USG alone had lower specificity but higher sensitivity in diagnosing benign lesions and higher specificity but lower sensitivity in diagnosing malignant lesions.
\end{abstract}

Keywords: Nodular goitre, USG, HPE.

\section{Introduction}

The diseases of the thyroid form a major share of head and neck surgery. Knowledge of the prevalence of thyroid disorders in the general population is based on clinical, epidemiological studies and autopsy series. Thyroid swellings may be diffuse or nodular. It is estimated that $4-7 \%$ adults have palpable enlargement of thyroid and 10 times more have impalpable nodules. Most of them are benign and fewer than 5\% are actually malignant.1 Current ultrasonography technology permits high resolution imaging of thyroid gland that is more accurate than clinical palpation or other imaging techniques. USG is safe and sensitive and capable of detecting lesions as small as $1-3 \mathrm{~mm}$ in the thyroid parenchyma.2

Although, ultrasound cannot reliably distinguish benign from malignant nodules, there are certain sonographic criteria that suggest malignancy. These include microcalcification, irregular margins and hypoechogenecity of the nodule. On the other hand, there are certain sonographic features that can aid in predicting the benign nature are hyperechogenecity, cystic nature of the nodule, well defined margins, coarse and eggshell calcifications, intact thin halo and comet tail sign.2

Here arises the need for histopathological examination, as it is considered the final diagnostic test. Thus even if non-surgical and non-invasive techniques can provide a diagnosis, the ultimate answer rests in the histopathological examination of the excised thyroid tissue. 3

The present study is undertaken to compare the efficacy of high resolution USG with the final HPE of the thyroid lesion.

\section{Materials And Methods}

Data collected prospectively from 30 consecutive patients who underwent surgery for thyroid disorders from January 2015 to December 2015, at S.S. Institute of Medical Sciences, Davangere, Karnataka. This study was approved by Institutional Ethical Committee. Patients with diffuse goitre and those who refused surgery were excluded from the study.

Routine blood investigations and specific investigations including high resolution USG and thyroid profile were done in all cases. High resolution $7.5-12 \mathrm{MHz}$ probe used for USG. Sonologically the nodules were evaluated for size, location, echotexture, margins, presence halo, calcification, vascularity, accessory nodules and associated cervical nodes and consistency of in order to differentiate from benign \& malignant nodules. All the patients were managed by surgery and diagnosis was confirmed by histopathological examination. 


\section{Results}

The age of patient ranged from 20 years to 60 years, with peaks being in $3^{\text {rd }}$ and $4^{\text {th }}$ decade. The mean age of presentation is 40.9 years. Nodular goitre of thyroid are much more common in females $(86.7 \%)$ with a sex ratio M: $\mathrm{F}=1: 6$. All the cases in the present study presented with the complaint of swelling in front of the neck. Only few patients presented with difficulty in swallowing and breathing, hoarseness, pain, hypothyroid and hyperthyroid features. The duration of swelling ranged from1 month to 6 years. Shortest duration was 1 month seen in 3 patients. Longest duration was 6years in 1 patient. Based on the clinical signs and symptoms, diagnosis of solitary thyroid nodule was made in $11(36.6 \%)$ patients, followed by thyroid cyst in $9(30 \%)$ patients, multinodular goitre in $6(20 \%)$, carcinoma in $3(10 \%)$ and thyroiditis in $1(3.4 \%)$. USG showed 29 (96.8\%) benign lesions and 1(3.3\%) malignant lesion. Most benign lesions were solitary colloid cystic (30\%) and solitary colloid $(26.7 \%)$, others like solitary cystic 5 (16.7), multinodular cystic $3(10 \%)$, multinodular colloid $2(6.7 \%)$, multinodular cystic colloid 2(6.7\%).

\begin{tabular}{|l|l|l|l|}
\hline & Ultrasound diagnosis & No. of Patients & Percentage \\
\hline 1 & Solitary cystic goiter & 5 & 16.7 \\
\hline 2 & Solitary colloid goitre & 8 & 26.6 \\
\hline 3 & Solitary cystic colloid goitre & 9 & 30.0 \\
\hline 4 & MNG cystic goiter & 3 & 10.0 \\
\hline 5 & MNG colloid goiter & 2 & 6.7 \\
\hline 6 & MNG cystic colloid goiter & 2 & 6.7 \\
\hline 7 & Carcinoma thyroid & 1 & 3.3 \\
\hline & Total & 30 & 100.0 \\
\hline
\end{tabular}

Table1: Ultrasound Diagnosis

HPE showed 26 (87\%) benign and $4(13 \%)$ malignant lesions. Benign lesions were solitary colloid 7 (23.5\%), solitary cystic 1 (3.35), solitary cystic colloid 7 (23.5\%), multinodular cystic 1 (3.3\%), multinodular colloid 4(13.3\%), multinodular cystic colloid 3 (10\%), follicular adenoma 4 (13.3\%) and malignant lesions papillary carcinoma $3(10 \%)$, follicular carcinoma $1(3.3 \%)$.

\begin{tabular}{|l|l|l|l|}
\hline & HPE diagnosis & No. of Patients & Percentage \\
\hline 1 & Solitary cystic & 1 & 3.3 \\
\hline 2 & Solitary colloid & 6 & 20.0 \\
\hline 3 & Solitary cystic colloid & 7 & 23.5 \\
\hline 4 & Multinodular cystic & 1 & 3.3 \\
\hline 5 & Multinodular colloid & 4 & 13.3 \\
\hline 6 & Multinodular cystic colloid & 3 & 10.0 \\
\hline 7 & Follicular Adenoma & 4 & 13.3 \\
\hline 8 & Follicular carcinoma & 1 & 3.3 \\
\hline 9 & Papillary Carcinoma & 3 & 10.0 \\
\hline & Total & 30 & 100.0 \\
\hline
\end{tabular}

Table2: Histopathology Diagnosis

Comparison between USG and HPE: USG showed 29 benign lesions. Among them 3 proved to be malignant on HPE. USG showed 1 malignant which was confirmed in HPE. USG shows higher sensitivity of $100 \%$, but lower specificity $25 \%$ for benign lesions and higher specificity of $100 \%$ but lower sensitivity $25 \%$ for malignant lesions.

\begin{tabular}{|l|l|l|l|}
\hline \multirow{2}{*}{ Usg } & \multicolumn{2}{|l|}{ Hpe } & \multirow{2}{*}{ Total } \\
\cline { 2 - 4 } & Benign & Malignant & \\
\hline Benign & 26 & 3 & 29 \\
\hline Malignant & 0 & 1 & 1 \\
\hline Total & 26 & 4 & 30 \\
\hline
\end{tabular}

Table 3: USG showed 29 benign lesions. Among them 3 proved to be malignant on HPE. USG showed 1 malignant which was confirmed in HPE.

Table 4: Sensitivity, Specificity, Ppv And Npv Of Usg Compared To Hpe

\begin{tabular}{|c|l|l|l|l|l|}
\hline & \multicolumn{1}{|c|}{ Sensitivity } & Specificity & PPV & NPV \\
\hline 1 & $\begin{array}{l}\text { Detection of benign } \\
\text { lesion by USG as } \\
\text { compared to HPE } \\
(95 \% \text { Confidence } \\
\text { Interval) }\end{array}$ & $\begin{array}{l}100 \% \\
(86.77-100 \%)\end{array}$ & $\begin{array}{l}25 \% \\
(0.63- \\
80.59 \%)\end{array}$ & $\begin{array}{l}89.66 \% \\
(72.65- \\
97.81 \%)\end{array}$ & $\begin{array}{l}100 \% \\
(2.50- \\
100 \%)\end{array}$ \\
\hline 2 & $\begin{array}{l}\text { Detection of malignant } \\
\text { lesions by USG as }\end{array}$ & $\begin{array}{l}25 \% \\
(0.63-80.59 \%)\end{array}$ & $\begin{array}{l}100 \% \\
(86.77-\end{array}$ & $\begin{array}{l}100 \% \\
(2.50-\end{array}$ & $\begin{array}{l}89.66 \% \\
(72.65-\end{array}$ \\
\hline
\end{tabular}




\begin{tabular}{|l|l|l|l|l|l|}
\hline $\begin{array}{l}\text { compared to HPE } \\
\text { Interval })\end{array}$ & $100 \%)$ & $100 \%)$ & $97.81 \%)$ \\
\hline
\end{tabular}

Sensitivity, specificity, positive predictive value and negative predictive value of USG in comparison to HPE for benign lesions were $100 \%, 25 \%, 89.66 \%$ and $100 \%$ and for malignant lesions were $25 \%, 100 \%, 100 \%$ and $89.66 \%$ respectively.

\section{Discussion}

In the present study age of the patient ranged from 20 to 60 years with mean age of $40.9 y e a r s$, comparable to the study done by Rangaswamy M et al. ${ }^{4}$ Sex ratio was M:F-1:6 correlating with the Yang et al study. ${ }^{5}$

In our study 29 were benign thyroid lesions, $25 \%$ anechoic, $20 \%$ hyper and hypoechoic, $10 \%$ isoechoic and 24\% mixed. Ankush Dhanadia et al50 in their study on 100 cases reported benign (88) thyroid lesions, $30.5 \%$ were anechoic, $25 \%$ each hyper and hypoechoic, $11 \%$ isoechoic and $8.3 \%$ mixed echogenicity. ${ }^{6}$

In our study peripheral halo seen in $6.8 \%$, calcification in $3.4 \%$ comet tail artefact in $6.8 \%$. Ankush et al in their study showed it to be $27 \%, 30.5 \%, 16.6 \%$ respectively. In present study single nodule was seen in $70 \%$ and multiple nodule in $22 \%$ in their study, according to Ankush et al it was $72.2 \%$ single and $22 \%$ multiple nodule, correlating with our study

In our study well defined margins seen in $76.8 \%$ and ill-defined in $23.2 \%$, in Ankush et al study $77.7 \%$ well defined and $22.3 \%$ ill defined. In our study solid lesions were $27 \%$, cystic in $37 \%$, solid-cystic in $20 \%$, in Ankush et al study it was $41.6 \%, 33.3 \%$ and $25 \%$ respectively. vascularity.

In present study vascularity was seen in $41 \%$ of cases. Ankush et al have not commented on

In our study only one was diagnosed to be malignant in USG showing hypoechogenecity, microcalcification, cystic and vascular. According to Ankush Dhanadia et al malignant cases 12 showing hypoechogenecity in 50\%, mixed echogenecity in $33.3 \%$ and isoechoic in $16.7 \%$, single nodule in $83.3 \%$, multiple nodule in $16.7 \%$, calcifications in $83.3 \%$, well defined and ill-defined margin in $50 \%$ each. $^{6}$

In present study it was $100 \%$ sensitivity and $25 \%$ specificity for benign lesions and $25 \%$ sensitivity and $100 \%$ specificity for malignant lesions. Ankush et al in their study concluded sensitivity and specificity of USG for malignant lesion to be $83.3 \%$ and $72.7 \%$. Our study did not correlate as number of cases we included were very less.

In the present study sensitivity, specificity, PPV and NPV of USG for benign lesions was 100\%, 25\%, $89.66 \%$ and $100 \%$, and for malignant lesions was $25 \%, 100 \%, 100 \%$ and $89.66 \%$ respectively. Venkatachalapathy.T.S ${ }^{7}$ in his prospective study of clinical, sonological and pathological evaluation of thyroid nodule in 200 cases concluded that sensitivity, specificity, PPV and NPV of USG is $84 \%, 77.7 \%, 94.28 \%$ and $46 \%$ for benign lesions, $73 \%, 85.3 \%, 52 \%$ and $93.3 \%$ for malignant lesions. Our study did not correlate with previous study mainly due to limited number of cases. In our study sensitivity and specificity of USG for malignant lesions were $25 \%$ and $100 \%$. Amer $\mathrm{AM} \mathrm{Ali}^{8}$ et al in their study on 233 cases reported sensitivity to be $80 \%$ and specificity to be $96 \%$. S Gurumani ${ }^{9}$ in his study on 50 cases concluded sensitivity of USG was $71.4 \%$ and specificity of $77.7 \%$

\section{Conclusion}

In the present study nodular goitre was more common in females. Nodular goitre was more common in the age group of 20-40 years. Commonest symptom was swelling in front of the neck. Most of the patients with nodular goitre were in euthyroid state. High resolution USG alone has lower specificity but higher sensitivity in diagnosing benign lesions and higher specificity but lower sensitivity in diagnosing malignant lesions. High resolution USG gives additional information regarding vascularity, displacement of the adjacent structures and cervical lymph nodes enlargement, which improved surgical outcome. However combination of high resolution USG and FNAC will yield optimum results.

\section{Acknowledgement}

We thank Department of Radiology and Pathology , S.S. Institute of Medical Sciences \& Research Centre, Davangere for support in carrying out this study.

\section{References}

[1]. Heyder Ali Esmaili, Hassan Taghipour. Fine needle aspiration in the diagnosis of thyroid disease- an appraisal in our institution. ISRN Pathology 2012.

[2]. Amer AM Ali, Abdul Khadir H Hasan, Tahir A Hawrami. The role of conventional ultrasound in the assessment of thyroid nodulesin Al-Sulaimainya territory. Bas J Surgery 2009. 
[3]. Dipanwita Das, MC Sarma, Adity Sharma, TK Datta, SK Lahiri. A Comparative study between fine needle aspiration cytology and histopathological examination in the diagnosis of neoplastic and nonneoplastic lesions of the thyroid gland. Indian J Prev Soc Med 2012; 43(1).

[4]. Rangaswamy M, Narendra KL, Patel S, Guruprasad C, Manjunath GV. Insight to neoplastic thyroid lesions by fine needle aspiration cytology. J Cytol 2013;30(1):23-6

[5]. Yang GC, Fried K, Yakoushina TV, Schreiner AM. Encapsulated follicular variant of papillary thyroid carcinoma- fine-needle aspiration with ultrasound and histologic correlation of 41 cases. Acta Cytol 2013; 57(1):26-32.

[6]. Ankush Dhanadia, Harshad Shah,Asutosh Dave. Ultrasonographic and FNAC correlations of thyroid lesions. Gujarat Medical J 2014; 69(1):75-81

[7]. Sreeramulu PN, Venkatachalapathy TS, Prathima S, Kishore Kumar. A Prospective study of clinical, sonological and pathological evaluation of thyroid nodule. J BioSci Tech 2012; 3(1):474-8

[8]. Amer AM Ali, Abdul Khadir H Hasan, Tahir A Hawrami. The role of conventional ultrasound in the assessment of thyroid nodulesin Al-Sulaimainya territory. Bas J Surgery 2009.

[9]. S.Gurumani. A comparative study of fine needle aspiration cytology, ultrasonography and radionuclide scan in management of solitary thyroid nodule -a prospective analysis of fifty cases. J of Evolution of Medical and Dental sciences 2013; 2(3):6207-14. 